\title{
NHIỄM TOAN CHUYỂN HÓA THEO KHOẢNG TRỐNG ANION
}

\author{
Nguyễn Tiến Mạnh, Phạm Văn Thắng* \\ *Bộ môn Nhi Đại học Y Hà Nội
}

\section{1. ĐẠI CƯƠNG}

Nhiễm toan chuyển hóa được định nghĩa là một quá trình bệnh lý, làm tăng nồng độ của các ion hydro trong cơ thể và làm giảm nồng độ $\mathrm{HCO}_{3}$. Toan chuyển hóa được chẩn đoán khi pH động mạch thấp $(<7,35), \mathrm{HCO}_{3}^{-}$thấp (<18mmol/l), $\mathrm{pCO}_{2}$ thấp $(<35 \mathrm{mmHg})$ và $\mathrm{BE}$ giảm. Kèm theo có /hoặc không các triệu chứng lâm sàng như thở nhanh sâu, nhịp thở Kussmaul, rối loạn thần kinh bao gồm nhức đầu, buồn nôn, lơ mơ, hôn mê và cuối cùng là trụy mạch $[5,6]$.

Theo A. Durward và CS có đến $46 \%$ số trẻ em nhập khoa ICU bị toan chuyển hóa [1]. Một nghiên cứu khác của $\mathrm{NaPa}$ và $\mathrm{CS}$ thì số trẻ em bị toan chuyển hóa là 27\% [1]. Theo Phí Đức Long và P.V.Thắng, tỷ lệ nhiễm toan chuyển hóa chiếm $51 \%$ tổng số trẻ nhiễm toan tại PICU [3].

Có nhiều nguyên nhân dẫn đến toan chuyển hóa với các biểu hiện lâm sàng khác nhau. Nhiễm toan nặng có thể gây nhiều biến chứng và dẫn đến tử vong nhanh chóng. Toan chuyển hóa ảnh hưởng lên rất nhiều cơ quan trong đó tim mạch là hệ cơ quan bị ảnh hưởng nặng nề nhất. Sức co bóp cơ tim và thể tích nhát bóp giảm, các chất giãn mạch được giải phóng gây hạ huyết áp. Sự suy giảm chức năng cơ tim xảy ra phụ thuộc vào $\mathrm{pH}$. Khi pH giảm từ 7,4 xuống 7,2 thể tích nhát bóp có thể tăng do các catecholamine được giải phóng, nhưng khi pH giảm xuống dưới 7,2 thì sự suy giảm thể tích nhát bóp chắc chắn sẽ xảy ra. Ngoài ra sự kháng các thuốc vận mạch cũng như các rối loạn nhịp thất cũng được ghi nhận ở những bệnh nhân toan chuyển hóa nặng [16].
Sự suy giảm ý thức, hôn mê cũng thấy ở những bệnh nhân toan chuyển hóa nặng mặc dù pH dịch não tủy chỉ thay đổi nhỏ. Toan chuyển hóa còn làm ảnh hưởng đến ái lực của gắn của oxy vào phân tử hemoglobin. Thời gian toan càng kéo dài, ái lực gắn càng giảm. Ngoài ra, trong toan chuyển hóa cấp tính, hoạt động của các tế bào lympho cũng như khả năng diệt khuẩn của bạch cầu bị suy giảm dẫn tới bệnh nhân dễ bị nhiễm trùng hơn. Ở những bệnh nhân này, toan chuyển hóa còn gây ra giảm hoạt động sản xuất ATP do ức chế 6-phosphofructokinase và thúc đẩy sự chết theo chương trình của tế bào [16].

Do những tác động xấu lên cơ thể nên những bệnh nhân toan chuyển hóa nếu không được điều trị kịp thời sẽ có tiên lượng rất xấu. Tiên lượng càng xấu khi mức độ toan càng nặng.

\section{SINH BỆNH HỌC}

2.1. Toan chuyển hóa bị sinh ra bởi ba cơ chế chính [3]

- Tăng sinh acid từ nguồn acid ngoại sinh (như salicylate) hoặc acid nội sinh (như acid lactic).

- Mất $\mathrm{HCO}_{3}^{-}$qua đường tiêu hóa (tiêu chảy) hoặc mất qua thận (toan hóa ống thận type 2).

- Giảm bài tiết acid ở thận do giảm mức lọc cầu thận (suy thận) hoặc mất khả năng acid hóa nước tiểu (toan hóa ống lượn xa).

2.2. Khả năng bù trừ của cơ thể với toan chuyển hóa 
TẠP CHÍ NHI KHOA 2021, 14, 2

\subsubsection{Khả năng bù trừ của hệ hô hấp}

Trong trường hợp toan chuyển hóa đơn độc, bù trừ của hệ hô hấp sẽ mang lại kết quả là giảm $\mathrm{pCO}_{2}$ từ đó đưa $\mathrm{pH}$ về mức bình thường. Phản ứng này bắt đầu ngay trong giờ đầu tiên và hoàn thành trong vòng 12 đến 24 giờ [7]. Bù trừ cấp tính sẽ đem lại kết quả là giảm $1,2 \mathrm{mmHg} \mathrm{pCO}_{2}$ cho mỗi $1 \mathrm{mEq} / \mathrm{l} \mathrm{HCO}_{3}^{-}$huyết thanh mất đi, hoặc mỗi $10 \mathrm{mmHg} \mathrm{pCO}_{2}$ giảm xuống sẽ làm tăng $\mathrm{pH}$ lên 0,08 [16]. Đáp ứng không tương xứng có thể tiềm ẩn nguy cơ của một bệnh lý hô hấp hoặc suy hô hấp sắp xảy đến [8].

Bệnh nhân bị toan chuyển hóa đơn độc sẽ có đáp ứng tương xứng của hệ hô hấp trong khi đó bệnh nhân bị toan chuyển hóa hỗn hợp sẽ có cả toan chuyển hóa và toan hô hấp. Đáp ứng của hệ hô hấp ở những bệnh nhân bị toan chuyển hóa đã tạo ra một mối quan hệ tuyến tính giữa $\mathrm{pCO}_{2}$ và $\mathrm{HCO}_{3}$. Kết quả là có một số phương pháp để phân biệt giữa toan chuyển hóa đơn độc và hỗn

A

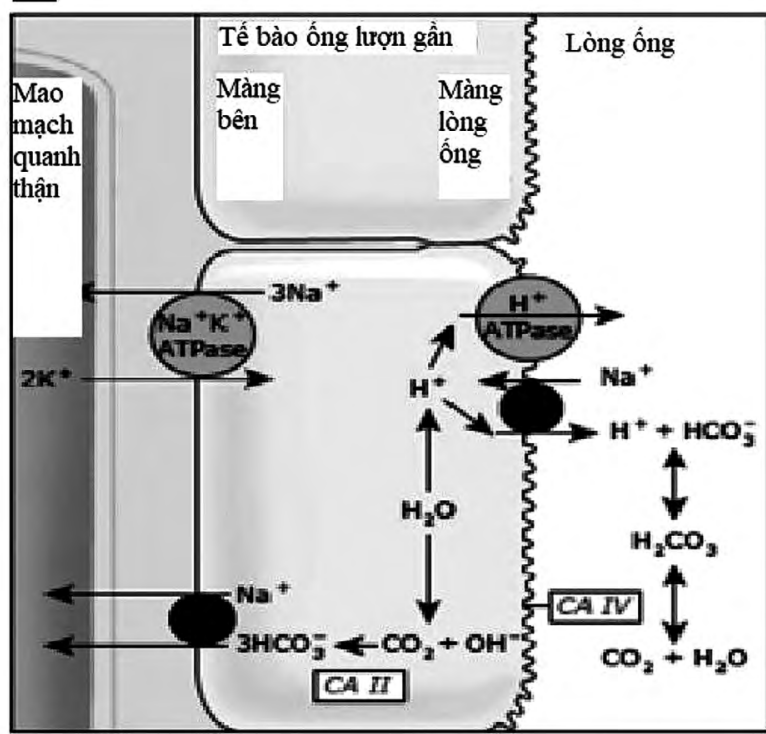

hợp ở những bệnh nhân không bị toan máu nặng $(\mathrm{pH}>7,1)[18]$ :

- Công thức Winter cho ta giá trị của $\mathrm{pCO}_{2}$ dựa trên $\mathrm{HCO}_{3}$ :

$$
\mathrm{pCO}_{2}=\left(1,5 \times\left[\mathrm{HCO}_{3}^{-}\right]\right)+8 \pm 2
$$

- Phương pháp thứ hai liên quan đến việc xác định tỷ lệ thay đổi tương đối của $\mathrm{HCO}_{3}^{-}$và $\mathrm{pCO}_{2}$, $\mathrm{pCO}_{2}$ thường giảm trung bình $1,2 \mathrm{mmHg}$ cho mỗi $1 \mathrm{mEq} / \mathrm{l} \mathrm{HCO}{ }_{3}^{-}$giảm, xuống mức $\mathrm{pCO}$ thấp nhất là khoảng 10-15 mmHg.

- Thứ ba là ước tính $\mathrm{pCO}_{2}$ phải xấp xỉ bằng hai chữ số cuối của pH cho đến mức pH là 7,1.

Tăng thông khí quá mức và giảm $\mathrm{pCO}_{2}$ một cách đáng kể là dấu hiệu của nhiễm toan chuyển hóa kết hợp với nhiễm kiềm hô hấp.

\subsection{2. Đáp ứng của thân}

Thận duy trì cân bằng acid base bằng cách tăng bài tiết acid ở thận và tăng tái hấp thu $\mathrm{HCO}_{3}$.

\section{B}

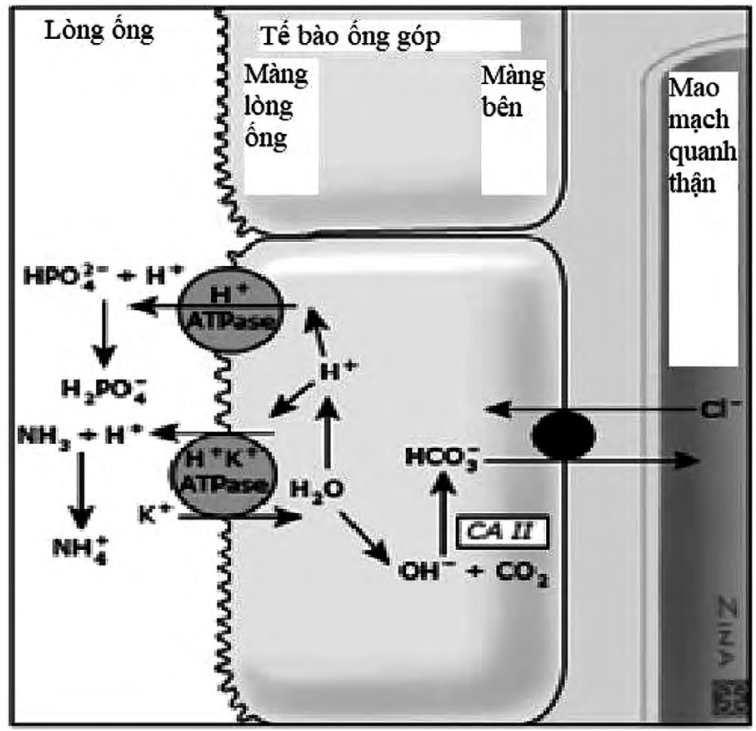

Hình 1. Hoạt động của tế bào ống thận [12]

- Tăng tái hấp thu $\mathrm{HCO}_{3}^{-}$ở ống lượn gần.

- Tăng bài tiết ion $\mathrm{H}^{+}$dưới dạng acid chuẩn độ (ví dụ acid phosphoric $\left[\mathrm{H}_{2} \mathrm{PO}_{4}^{-}\right]$) hoặc $\mathrm{NH}_{4}{ }^{+}$ để tái hấp thu $\mathrm{HCO}_{3}^{-}$trong ống thận, từ đó đưa
$\mathrm{HCO}_{3}^{-}$quay trở lại vòng tuần hoàn nhờ mao mạch quanh ống thận.

ở những người bình thường, tốc độ bài tiết acid và amoni chuẩn độ gần bằng với lượng acid 
trong chế độ ăn hàng ngày. Khi tải lượng acid tăng lên, thận có thể bù lại bằng cách tăng bài tiết amoni. Bài tiết acid ở thận bị suy giảm do suy thận hoặc mất khả năng acid hóa tối đa nước tiểu do toan hóa ống thận dẫn đến nhiễm toan chuyển hóa.

\section{TOAN CHUYỂN HÓA DỰA TRÊN ANION GAP}

\subsection{Khái niệm}

Khoảng trống anion ( $\mathrm{AG}$ ) được sử dụng để phân loại nguyên nhân nhiễm toan chuyển hóa thường được tính là sự khác biệt giữa cation chính là natri $\left(\mathrm{Na}^{+}\right)$và các anion đo được chủ yếu là clo $\left[\mathrm{Cl}^{-}\right]$và bicarbonate $\left[\mathrm{HCO}_{3}^{-}\right]$:

$$
\text { AG }(\mathrm{mEq} / \mathrm{l})=\left(\mathrm{Na}^{+}\right)-\left(\mathrm{Cl}^{-}+\mathrm{HCO}_{3}^{-}\right)[13]
$$

Một số nơi sử dụng kali $(K)$ thêm cùng với natri trong tính toán của AG. Trong những trường hợp như vậy, giá trị AG bình thường tăng thêm $4 \mathrm{mEq} / \mathrm{L}$.

Giá trị AG tăng cao thường là do sự gia tăng các anion không đo lường được (ví dụ, lactate, beta-hydroxybutyrate) trong máu [10]. Mặc dù AG cũng có thể được tăng lên do giảm $\mathrm{K}^{+}$huyết thanh, calci (Ca) hoặc magiê ( $\mathrm{Mg}$ ), nồng độ trong huyết thanh của các cation này tương đối thấp và việc giảm nồng độ của chúng có ảnh hưởng không đáng kể đến AG. Ở trẻ em, AG trên 14 đến $16 \mathrm{mEq} / \mathrm{L}$ được coi là tang [20]. ở trẻ sơ sinh, AG trên $16 \mathrm{mEq} / \mathrm{L}$ được coi là tăng và giá trị tăng lên là do sự hiện diện của nhiễm toan lactic nhẹ [11]. Giá trị AG thấp có thể được tạo ra bằng cách giảm các anion không đo được (hạ albumin máu), hoặc tăng các cation không phải natri (tăng kali máu, tăng calci máu, tăng magiê máu) [19].

\subsection{Nguyên nhân gây toan chuyển hóa có $A G$ cao}

Nhiễm toan chuyển hóa AG cao dẫn đến sự gia tăng các anion không đo lường được dẫn đến tích tụ ion hydro trong máu. Các nguyên nhân gây nhiễm toan chuyển hóa tăng AG ở trẻ em bao gồm $[12,6]$ :
- Do tăng sản xuất acid hữu cơ: đái tháo đường, suy hô hấp, sốc.

+ Nhiễm acid lactic do giảm tưới máu do nhiễm trùng huyết, suy tim hoặc hạ kali máu nặng. Tăng acid lactic cũng có thể được nhìn thấy ở những bệnh nhân bị rối loạn ty thể $[10,13]$ và ở trẻ sơ sinh bị thiếu oxy và thiếu máu cục bộ chu $\sinh$ [14].

+ Toan ceton do đái tháo đường (DKA) là kết quả của sự tích tụ acid acetoacetic và acid betahydroxybutyric [15].

- Do giảm tiết $\mathrm{H}^{+}$: suy thận, bệnh thận cấp tính và mạn tính có liên quan đến việc giữ lại cả các ion hydro và các anion không đo lường được, chẳng hạn như sulfate, phosphate và urate [16].

- Do nhiễm độc: uống phải các chất độc liên quan đến nhiễm toan chuyển hóa AG cao bao gồm methanol, ethylene glycol và ngộ độc salicylate. Các chất này được chuyển đổi thành các anion làm tăng $A G$ dưới dạng formate (methanol), glycolate, oxalate (ethylene glycol), ketone và lactate (salicylate) $[17,18]$.

- Rối loạn chuyển hóa bẩm sinh bao gồm rối loạn chuyển hóa acid amin, carbohydrate hoặc acid béo. Tăng lactat cũng gặp trong các bệnh nhân rối loạn chuyển hóa do làm bất hoạt enzyme pyruvat dehydrogenase. Ngoài ra các trường hợp giảm độ thanh thải của lactat ở gan như sốc nặng, thiếu hụt enzyme chuyển hóa, ngộ độc cyanide cũng gây ra toan chuyển hóa [19].

Theo N.T.Mạnh (2020) nghiên cứu về nguyên nhân toan chuyển hóa theo AG tại khoa PICU BV Nhi TU, cho thấy nguyên nhân hay gặp nhất của nhiễm toan chuyển hóa là tình trạng sốc, trong đó sốc nhiễm khuẩn là thường gặp nhất. Tiếp theo là rối loạn chuyển hóa. Ngoài ra còn nguyên nhân khác chiếm tỷ lệ thấp hơn.

Nhóm bệnh nhân nhiễm toan chuyển hóa tăng $\mathrm{AG}$ chủ yếu nằm trong nhóm tăng sản xuất 
acid. Số bệnh nhân có AG tăng chiếm 76\%. Trong đó bệnh nhân có $A G$ từ 12-20 chiếm tỷ lệ cao nhất. Tiếp theo là nhóm giảm chuyển hóa acid chiếm và nhóm giảm bài tiết acid [28].

3.3. Nguyên nhân gây nhiễm toan chuyển hóa có AG bình thường

Nhiễm toan chuyển hóa với AG bình thường là do mất $\mathrm{HCO}_{3}^{-}$hoặc suy giảm bài tiết $\mathrm{H}^{+}$trong trường hợp không bị suy thận. ở những bệnh nhân bị mất $\mathrm{HCO}_{3}$; thận tăng khả năng giữ $\mathrm{Cl}^{-}$ bù cho lượng $\mathrm{HCO}_{3}^{-}$mất đi để duy trì cân bằng điện tích. Do đó, tăng clo máu là một phát hiện đặc trưng của nhiễm toan chuyển hóa AG bình thường. Nhóm bệnh nhân mất kiềm thường gặp các triệu chứng sốt, nôn, tiêu chảy.

Nguyên nhân gây toan chuyển hóa có AG bình thường bao gồm $[12,6]$ :

- Do mất kiềm: ở trẻ em, tiêu chảy là nguyên nhân phổ biến nhất gây mất $\mathrm{HCO}_{3}$; tiếp theo là toan ống thận (type 2).

- Do tăng $\mathrm{HCl}$ : dùng $\mathrm{NH}_{4} \mathrm{Cl}$, acid amin.

- Do tích acid: nhiễm toan ống thận (type 1 và type 4).

\subsection{Nhiễm toan chuyển hóa do nguyên nhân hỗn hợp.}

Rối loạn hỗn hợp xảy ra khi có các nguyên nhân đồng thời của nhiễm toan chuyển hóa AG bình thường và cao trong cùng một bệnh nhân. Những rối loạn này thường khó chẩn đoán phân biệt với nhiễm toan chuyển hóa $A G$ cao vì cả hai đều có $A G$ tăng cao. Phổ biến nhất trong nhi khoa của rối loạn hỗn hợp là tiêu chảy nặng ( $\mathrm{AG}$ bình thường có $\mathrm{HCO}_{3}^{-}$thấp) kèm theo nhiễm acid lactic (AG cao) do giảm tưới máu là kết quả của giảm kali máu do mất dịch đường tiêu hóa nghiêm trọng.

Tỷ lệ $\Delta \mathrm{AG} / \Delta \mathrm{HCO}_{3}$ - là tỷ lệ về sự thay đổi của $\mathrm{AG}$ so với sự thay đổi của $\mathrm{HCO}_{3}{ }_{3}^{-}$có thể giúp ích trong việc phân biệt sự khác nhau giữa toan chuyển hóa AG hỗn hợp và toan chuyển hóa tăng AG. ở những bệnh nhân bị nhiễm toan chuyển hóa AG tăng cao (Trong toan ceton đái tháo đường, bệnh thận mạn, ngộ độc methanol), tỷ lệ này thường nằm trong khoảng từ 1 đến 1,6 , vì cứ tăng $1 \mathrm{mEq} / \mathrm{L}$ trong anion thì $\mathrm{HCO}_{3}^{-}$giảm bằng một lượng tương ứng [20].

\section{TRIỆU CHỨNG LÂM SÀNG}

\subsection{Triệu chứng lâm sàng chung}

Không có đặc điểm lâm sàng riêng biệt cho nhiễm toan chuyển hóa ở trẻ em. Thông thường trẻ có các triệu chứng liên quan đến tình trạng bệnh nền. Trong nhiễm acid lactic thường có các triệu chứng và dấu hiệu liên quan đến tưới máu mô kém, chi lạnh hoặc hạ huyết áp, do nhiễm khuẩn huyết hoặc sốc. Các triệu chứng suy tuần hoàn như hạ huyết áp, refill kéo dài hay gặp ở nhóm bệnh nhân tăng sản xuất acid như sốc, suy hô hấp.

Những phát hiện lâm sàng chính của nhiễm toan chuyển hóa cấp tính là do bù trừ của hệ hô hấp. Trẻ lớn hơn biểu hiện sự gia tăng tần số hô hấp (thở nhanh) và độ sâu của nhịp thở (ví dụ, nhịp thở Kussmaul).

- Nhiễm toan chuyển hóa do bất kỳ nguyên nhân nào cũng làm suy giảm sự tăng trưởng và phát triển của trẻ.

\subsection{Trẻ sơ sinh}

Trẻ sơ sinh dễ bị nhiễm toan chuyển hóa hơn trẻ lớn vì những lý do sau:

-Trẻ sơ sinh có ngưỡng tái hấp thu bicarbonate ở ống thận thấp hơn, dẫn đến tỷ lệ tái hấp thu bicarbonate được lọc qua câuu thận ít hơn so với trẻ lớn. Kết quả là, trẻ sơ sinh có $\mathrm{HCO}_{3}^{-}$bình thường $\left(\mathrm{HCO}_{3}^{-}\right)$thấp hơn so với trẻ lớn và người lớn (20 so với $24 \mathrm{mEq} / \mathrm{L})$. Tương tự, áp suất riêng phần bình thường của carbon dioxide $\left(\mathrm{pCO}_{2}\right)$ ở trẻ sơ sinh thấp hơn ở trẻ lớn (35 so với $40 \mathrm{mmHg}$ ). 
- Sự bài tiết acid tối đa ở ống lượn xa bị hạn chế ở trẻ nhỏ và trẻ sơ sinh.

- Trẻ nhỏ và trẻ sơ sinh có lượng acid trong chế độ ăn và sản phẩm acid nội sinh trên mỗi kg cân nặng cao hơn người lớn [31].

Những đặc điểm sinh lý của trẻ sơ sinh, đặc biệt là những trẻ sinh non, cho ta thấy:

- Trẻ nhỏ và trẻ sơ sinh có nhiều hạn chế hơn trong việc bù trừ cho lượng acid dư thừa hoặc cho lượng bicarbonate mất đi (tiêu chảy).

- Sự tái hấp thu và bài tiết qua đường tiêu hóa của chế độ ăn đóng một vai trò quan trọng trong cân bằng nội môi acid ở trẻ sơ sinh. Chế độ ăn chủ yếu là sữa đóng góp một lượng kiềm đáng kể ở trẻ sơ sinh. Do đó, trẻ sơ sinh dễ bị nhiễm toan chuyển hóa trong các bệnh liên quan đến giảm lượng sữa ăn vào và mất quá mức qua đường tiêu hóa (tiêu chảy).

ở trẻ nhỏ và trẻ sơ sinh, sự gia tăng độ sâu của nhịp thở có thể không rõ ràng và phản ứng duy nhất đối với nhiễm toan chuyển hóa có thể là thở nhanh.

\section{CHẨN ĐOÁN}

\subsection{Chẩn đoán xác định}

Nhiễm toan chuyển hóa được xác định bằng các xét nghiệm máu có pH huyết thanh/huyết tương thấp hơn 7,35 và nồng độ bicarbonate thấp bất thường $\left(\mathrm{HCO}_{3}^{-}\right)$. Ngưỡng cho $\mathrm{HCO}_{3}^{-}$thấp bất thường ở trẻ sơ sinh ( $<20 \mathrm{mEq} / \mathrm{L}$ ) thấp hơn ở trẻ lớn và người lớn (22 mEq/L).

Phân tích khí máu: xác định chẩn đoán nhiễm toan chuyển hóa dựa trên những tiêu chuẩn sau [26]:
- Giảm pH máu $(<7,35)$

- Giảm nồng độ $\mathrm{HCO}_{3}{ }_{3}^{-}$trong máu

- Giảm áp suất riêng phần của $\mathrm{CO}_{2}\left(\mathrm{pCO}_{2}\right)$, với sự bù trừ của hô hấp, sự giảm $\mathrm{PCO}_{2}$ thường là khoảng $1 \mathrm{mmHg}$ cho mỗi $1 \mathrm{mmol} / \mathrm{HCO}_{3}^{-}$giảm trong huyết thanh.

\subsection{Tiếp cận chẩn đoán}

Hỏi bệnh chi tiết, khám thực thể và xét nghiệm cơ bản trong phòng thí nghiệm thường là đủ để xác định nguyên nhân cơ bản. Tuy nhiên, trong một số trường hợp, cần xét nghiệm chẩn đoán thêm dựa trên kết quả ban đầu (khoảng trống anion $[A G]$ ) là cần thiết.

\subsubsection{Bệnh sử}

Thường có bằng chứng về nguyên nhân của nhiễm toan chuyển hóa có thể định hướng được thông qua khai thác bệnh sử.

\subsubsection{Tiền sử}

Tiền sử tiêu chảy có thể là dấu hiệu mất bicarbonate hoặc tăng tiết lacic do giảm thể tích máu.

- Chẩn đoán toan ceton do đái tháo đường có thể được gợi ý bởi tiền sử đa niệu có hoặc không có giảm cân, đau bụng và nôn.

- Chậm phát triển là vấn đề hay gặp ở bệnh nhân bệnh thận mạn hoặc toan hóa ống thận.

- Tiền sử giảm trương lực cơ nặng, co giật, chậm phát triển hoặc ngưng thở ở trẻ sơ sinh có thể gợi ý về một rối loạn chuyển hóa bẩm sinh, đặc biệt là rối loạn ty thể.

- Cần phải điều tra tiền sửngộ độc do vô ý hoặc cố ý ở những bệnh nhân bị nhiễm toan chuyển hóa đột ngột và bất ngờ. 


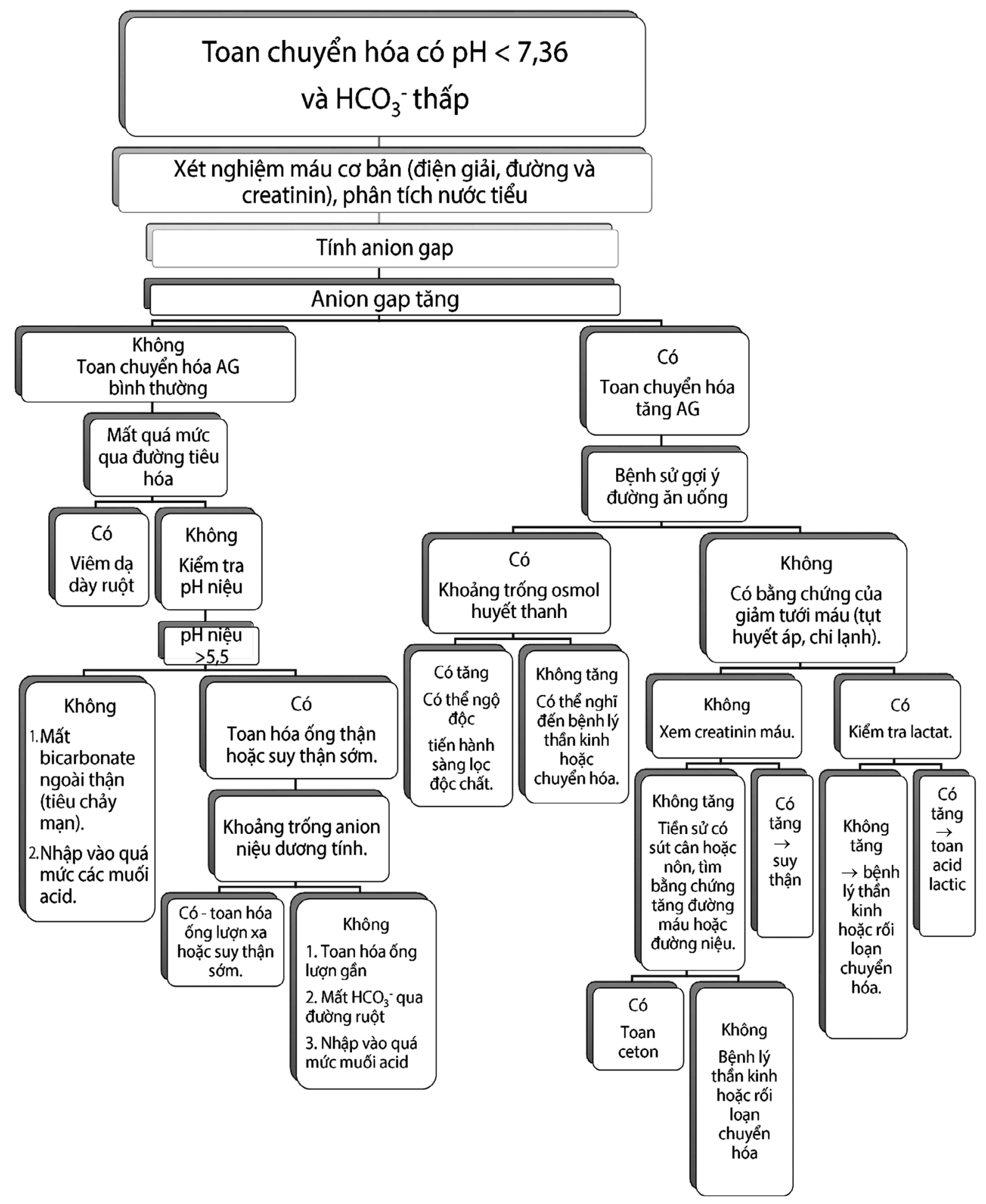

Lưu đồ 1. Tiếp cận bệnh nhân toan chuyển hóa 


\subsubsection{Khám thực thể}

Tìm kiếm các dấu hiệu thực thể có thể giúp ích cho việc chẩn đoán nguyên nhân bao gồm: chậm phát triển gợi ý các bệnh mạn tính như bệnh thận mạn hoặc toan hóa ống thận, tăng huyết áp có thể gặp ở bệnh nhân tổn thương thận cấp hoặc bệnh thận mạn, nhịp tim nhanh, chi lạnh và huyết áp thấp có thể là dấu hiệu của giảm tưới máu dẫn đến nhiễm acid lactic. Suy hô hấp cấp, nặng dẫn tới tình trạng thiếu oxy máu, gây ra chuyển hóa yếm khí cũng làm tăng acid lactic của bệnh nhân.

\subsubsection{Cận lâm sàng}

- Điện giải và khoảng trống anion: Giá trị các chất điện giải thu được dùng để tính AG. AG giúp xác định nguyên nhân cơ bản bằng cách phân chia các rối loạn dựa trên AG bình thường hoặc tăng. Sự khác biệt này có thể giúp quyết định xem xét nghiệm cận lâm sàng nào sẽ hữu ích hơn.

- Xét nghiệm chức năng thận: Đánh giá chức năng thận là một phần không thể thiếu trong đánh giá bệnh nhân nhiễm toan chuyển hóa, vì cả $A K I$ và $C K D$ đều có thể liên quan đến nhiễm toan chuyển hóa. Điều quan trọng cần lưu ý là AG trong $C K D$ sớm có thể bình thường nhưng thường tăng ở CKD tiến triển do giữ lại các anion, chẳng hạn như phosphate, sulfate, urate và hippurat.

- Xét nghiệm nước tiểu:Tim kiếm trong nước tiểu những bằng chứng có thể giúp xác định nguyên nhân gây nhiễm toan chuyển hóa bao gồm:

+ Glucose niệu xuất hiện ở những đứa trẻ bị toan ceton do đái tháo đường.

+ Tỷ trọng nước tiểu thấp, đặc biệt ở trẻ em có bằng chứng giảm thể tích, được thấy ở trẻ em bị suy giảm khả năng cô đặc nước tiểu, đây có thể là biểu hiện của bệnh lý thận tiềm ẩn.

+ Độ $\mathrm{pH}$ nước tiểu cao bất thường $(>6,5)$ là biểu hiện của acid hóa nước tiểu kém hoặc tăng $\mathrm{HCO}_{3}^{-}$thận, đó là những phát hiện liên quan đến RTA. Phản ứng thích hợp của thận đối với nhiễm toan chuyển hóa là tăng bài tiết acid trong nước tiểu, với pH nước tiểu giảm xuống dưới 5,5 và thường dưới 5,0.

- Xét nghiệm chẩn đoán dựa trên khoảng trống anion:

+ Tăng khoảng trống anion: Các nghiên cứu để xác định nguyên nhân của nhiễm toan chuyển hóa AG cao bao gồm các xét nghiệm sau:

- Lactat huyết thanh: Bệnh nhân trong nhóm tăng sản xuất acid gồm nhiễm trùng huyết, sốc và suy hô hấp thường bị nhiễm toan chuyển hóa do tưới máu mô kém, dẫn đến tăng sản xuất lactat.

- Khoảng trống osmol huyết thanh được tính theo công thức sau:

SOG $=(2 \times[\mathrm{Na}])+($ glucose $[\mathrm{mg} / \mathrm{dl}]) / 18+($ ure $[\mathrm{mg} / \mathrm{dl}]) / 2,8$

Khoảng cách thẩm thấu bình thường thường $<10$ [32]

- Nhiễm toan chuyển hóa ở nhóm không chuyển hóa được acid gồm các bệnh nhân ngộ độc và rối loạn chuyển hóa bẩm sinh.

Ngộ độc: Một số loại thuốc và độc chất như salicylat, metanol, ethylene glycol, isopropyl alcohol, butoxyethanol và toluene, có thể dẫn đến nhiễm toan chuyển hóa $A G$ cao và $S O G>10$. Nếu SOG tăng, việc đo các độc tố này và các chất chuyển hóa của chúng trong máu và nước tiểu có thể là cần thiết.

Các rối loạn chuyển hóa bẩm sinh: Nhiều rối loạn sai sót bẩm sinh của quá trình trao đổi chất (ví dụ, rối loạn chuyển hóa acid amin) có liên quan đến nhiễm toan chuyển hóa AG cao.

+ Khoảng trống anion gap bình thường: Hầu hết các trường hợp bị nhiễm toan AG bình thường là do mất kiềm. Tuy nhiên, trong nhứng trường hợp không được chẩn đoán, khoảng trống anion trong nước tiểu (UAG) có thể hữu ích để phát hiện sự suy giảm bài tiết $\mathrm{H}^{+}$ra nước tiểu.

Khoảng trống anion niệu và điện giải đồ niệu: Ở những bệnh nhân bị nhiễm toan AG bình thường, UAG có thể hữu ích để phát hiện xem có 
sự suy yếu trong bài tiết amoni ( $\left.\mathrm{NH}^{+}\right)$hay không, như thấy trong RTA ống lượn xa (loại 1). UAG được tính bằng công thức sau:

$$
\text { UAG }(\mathrm{mEq} / \mathrm{l})=(\mathrm{Na}+\mathrm{K}-\mathrm{Cl}) \text { niệu }
$$

- Giá trị UAG âm cho thấy bài tiết ammonium trong nước tiểu còn nguyên vẹn. Phản ứng của thận bình thường đối với nhiễm toan chuyển hóa là tăng sản xuất amoniac $\left(\mathrm{NH}_{3}\right)$, giúp tăng cường bài tiết ion hydro dưới dạng amoni clorua $\left(\mathrm{NH}_{4} \mathrm{Cl}\right)$. Vi clorua đi kèm với amoni clorua $\left(\mathrm{NH}_{4} \mathrm{Cl}\right)$, bất kỳ sự gia tăng nồng độ $\mathrm{Cl}$ trong nước tiểu đều dẫn đến số UAG âm tính. Ngược lại, sản xuất $\mathrm{NH}_{4}$ ở thận thấp không phù hợp trong nhiễm toan chuyển hóa được đặc trưng bởi $\mathrm{Cl}$ niệu thấp và giá trị UAG dương. Một UAG dương tính thường thấy ở những bệnh nhân mắc RTA ống lượn xa (loại 1), trong khi UAG âm tính (bình thường) được thấy ở những bệnh nhân mắc RTA ống lượn gần (loại 2).

- UAG cũng giúp xác nhận mất bicarbonate ngoài thận là nguyên nhân gây nhiễm toan chuyển hóa, chẳng hạn như ở bệnh nhân bị tiêu chảy. Nhiễm toan chuyển hóa AG bình thường trong tiêu chảy là kết quả của mất bicarbonate trong phân. Sản xuất ammonium thận ở những bệnh nhân như vậy bình thường và UAG dự kiến sẽ âm tính (thường > -20 mEq / L).

\section{6. ĐIỀ TR!}

Can thiệp điều trị hiệu quả nhất ở bệnh nhân nhiễm toan chuyển hóa là điều trị nguyên nhân cơ bản, phục hồi tưới máu đầy đủ ở bệnh nhân nhiễm toan acid lactic do giảm tưới máu, hoặc điều trị bằng insulin và bù dịch cho bệnh nhân nhiễm toan đái tháo đường (DKA). Trong một số trường hợp, rối loạn không thể được điều chỉnh và cần phải điều trị bằng kiềm (nhiễm toan ở ống thận [RTA], bệnh thận mạn tính [CKD]). Các phương pháp điều trị cụ thể cho các nguyên nhân cơ bản của nhiễm toan chuyển hóa được xem xét riêng:

Toan chuyển hóa mạn tính: Nhiễm toan chuyển hóa dai dẳng do RTA hoặc CKD được điều trị bằng liệu pháp uống kiềm [23]. Các lựa chọn bao gồm muối natri hoặc kali của bicarbonate hoặc anion chuyển hóa như citrate hoặc lactate.
Toan chuyển hóa cấp tính: Việc điều trị nhiễm toan chuyển hóa cấp tính vẫn còn gây tranh cãi, vì không có đồng thuận chung về liệu pháp tối ưu, đặc biệt là với liệu pháp tiêm kiềm tĩnh mạch.

Liệu pháp bicarbonate: Sử dụng liệu pháp bicarbonate vẫn còn gây tranh cãi, vì có những lo ngại về tác dụng phụ tim mạch bất lợi, dựa trên dữ liệu từ các nghiên cứu trên động vật. Chúng bao gồm suy giảm khả năng co bóp của tim, tăng nguy cơ rối loạn nhịp tim, giảm sức cản mạch máu ngoại biên và huyết áp, suy giảm đáp ứng tim mạch với catecholamine và mỏi cơ do tăng thông khí [24]. Do đó, sự cân bằng giữa lợi ích và tác dụng phụ của liệu pháp bicarbonate trong điều trị nhiễm toan chuyển hóa nặng phải được cân nhắc cẩn thận ở bệnh nhi, đặc biệt là ở trẻ sơ sinh.

Đối với trẻ em trong đơn vị chăm sóc đặc biệt (ICU), thường dùng liệu pháp bicarbonate tiêm tĩnh mạch (IV) để điều chỉnh nhiễm toan nặng khi $\mathrm{pH}<7,1$ [24,26]. Ở những bệnh nhân ít nguy kịch hơn, liệu pháp bicarbonate có thể được đưa ra ở các giá trị pH cao hơn nhưng quyết định dựa trên từng trường hợp cụ thể.

Giám sát việc sử dụng bicarbonate đường tĩnh mạch ở trẻ em bị nhiễm toan chuyển hóa nặng:

- Ở những bệnh nhân bị nhiễm acid lactic gây sốc và $\mathrm{pH}$ tînh mạch $<7,1$, có thể cân nhắc sử dụng bicarbonate thận trọng cùng với thông khí đầy đủ và phục hồi tưới máu mô.

- Điều trị bằng bicarbonate thường không được khuyến cáo ở những bệnh nhân mắc toan ceton đái tháo đường, trừ khi có một tình trạng có khả năng đe dọa đến tính mạng.

- Việc điều trị rối loạn chuyển hóa acid amin hữu cơ rất phức tạp, tùy thuộc vào khiếm khuyết chuyển hóa ở bệnh nhân. Sử dụng liệu pháp bicarbonate đường tĩnh mạch để điều trị nhiễm toan chuyển hóa cần được xem xét trong các trường hợp lâm sàng riêng lẻ, và thường kết hợp với các phác đồ điều trị cụ thể.

- Liệu pháp bicarbonate có thể được sử dụng như liệu pháp bổ trợ trong điều trị tăng kali máu cấp tính. 
- Liều dùng nếu được chỉ định, natri bicarbonate được tiêm tĩnh mạch với liều 0,5 đến $1 \mathrm{mEq} / \mathrm{kg}$ trọng lượng cơ thể. Mục tiêu của điều trị ban đầu là nâng cao và duy trì $\mathrm{pH}$ tĩnh mạch trên 7,2. Chú ý chỉ bù khi toan hô hấp đã được giải quyết, không truyền chung đường truyền với calcium, dopamin, dobutamin, thử lại khí máu và điện giải đồ sau bù [14].

\section{TIÊN LƯợNG}

Tiên lượng của bệnh nhân nhiễm toan chuyển hóa phụ thuộc vào nguyên nhân gây bệnh và mức độ nặng của rối loạn thăng bằng kiềm toan [25].

Theo N.T.Mạnh (2020), bệnh nhân nhiễm toan chuyển hóa có tỷ lệ tử vong cao chiếm $60,1 \%$. Nhóm AG > 30 có tỷ lệ tử vong cao hơn.

Nhóm bệnh nhân tử vong có $A G$ cao hơn trong khi pH, tiểu cầu thấp hơn nhóm sống. Khoảng trống anion có giá trị dự đoán tỷ lệ tử vong tương đương với các thang điểm PIM3 và PRISM3 [28].

Kira và cộng sự khi nghiên cứu trên những bệnh nhân toan chuyển hóa nặng, pH<7,2, cho thấy tỷ lệ tử vong lên tới $70 \%$. Việc giám sát thường xuyên các chỉ số trong khí máu như pH, $\mathrm{HCO}_{3}^{-}$, $\mathrm{BE}$ và lactat góp phần tiên lượng bệnh nhân và đưa ra những liệu pháp xử trí thích hợp [28]. Tuy vậy nếu được phát hiện sớm và xử lý đúng, bệnh nhân có thể phục hồi hoàn toàn.

\section{TÀI LIỆU THAM KHẢO}

1. Balasubramanyan $\mathrm{N}$, Havens $\mathrm{PL}$, Hoffman GM. Unmeasured anions identified by the FenclStewart method predict mortality better than base excess, anion gap, and lactate in patients in the pediatric intensive care unit. Crit Care Med. 1999; 27(8): 1577-1581. doi: 10.1097/00003246199908000-00030.

2. Kliegman R, Behrman RE, Nelson WE, eds. Nelson Textbook of Pediatrics. Edition 20. Elsevier; 2016.
3. Phí Đức Long, Phạm Văn Thắng. Nhận xét về nguyên nhân và kết quả điều trị nhiễm toan ở trẻ em tại khoa Hồi sức cấp cứu Viện Nhi. Luận văn Thạc sĩ y học. Đại học Y Hà Nội. 2002.

4. Hall JE. Guyton and Hall Textbook of Medical Physiology.13th edition. Elsevier; 2016.

5. Jung B, Martinez $M$, Claessens $Y-E$, et al. Diagnosis and management of metabolic acidosis: guidelines from a French expert panel. Ann Intensive Care. 2019;9. doi:10.1186/s13613019-0563-2.

6. Phạm Văn Thắng. Rối loạn thăng bằng kiềm toan, Bài giảng Nhi khoa sau Đại học. Nhà xuất bản Y học Việt Nam; 2017.

7. Pierce NF, Fedson DS, Brigham KL, Mitra RC, Sack RB, Mondal A. The ventilatory response to acute base deficit in humans. Time course during development and correction of metabolic acidosis. Ann Intern Med. 1970; 72(5): 633-640. doi: 10.7326/0003-4819-72-5-633.

8. Bushinsky DA, Coe FL, Katzenberg C, Szidon JP, Parks JH. Arterial PCO2 in chronic metabolic acidosis. Kidney Int. 1982; 22(3): 311-314. doi: 10.1038/ki.1982.172.

9. Fulop M. A guide for predicting arterial $\mathrm{CO} 2$ tension in metabolic acidosis. Am J Nephrol. 1997;17(5):421-424. doi:10.1159/000169134.

10. Kraut JA, Madias NE. Lactic acidosis. N Engl J Med. 2014; 371(24): 2309-2319. doi: 10.1056/NEJMra1309483.

11. Lorenz JM, Kleinman LI, Markarian K, Oliver $\mathbf{M}$, Fernandez $\mathrm{J}$. Serum anion gap in the differential diagnosis of metabolic acidosis in critically ill newborns.J Pediatr. 1999;135(6): 751755. doi:10.1016/s0022-3476(99)70096-x.

12. Phạm Văn Thắng. Rối loạn kiềm toan ở trẻ em, Hướng dẫn chẩn đoán và điều trị bệnh trẻ em. Bệnh viện Nhi Trung ương. 2018.

13. Noritomi DT, Soriano FG, Kellum JA, et al. Metabolic acidosis in patients with severe sepsis and septic shock: a longitudinal quantitative study. Crit Care Med. 2009;37(10):2733-2739. doi:10.1097/ccm.0b013e3181a59165. 
14. Murray DM, Boylan GB, Fitzgerald AP, Ryan CA, Murphy BP, Connolly S. Persistent lactic acidosis in neonatal hypoxic-ischaemic encephalopathy correlates with EEG grade and electrographic seizure burden. Arch Dis Child Fetal Neonatal Ed. 2008;93(3):F183-186. doi:10.1136/adc.2006.100800.

15. Palmer BF, Clegg DJ. Electrolyte and Acid-Base Disturbances in Patients with Diabetes Mellitus.N Engl J Med. 2015;373(6):548-559. doi:10.1056/NEJMra1503102.

16. Kraut JA, Madias NE. Metabolic acidosis: pathophysiology, diagnosis and management. Nat Rev Nephrol. 2010;6(5):274-285. doi:10.1038/ nrneph.2010.33.

17. Jammalamadaka D, Raissi S. Ethylene glycol, methanol and isopropyl alcohol intoxication. Am J Med Sci. 2010;339(3):276-281. doi:10.1097/MAJ.0b013e3181c94601.

18. O'Malley GF. Emergency department management of the salicylate-poisoned patient. Emerg Med Clin North Am. 2007;25(2):333-346; abstract viii. doi:10.1016/j.emc.2007.02.012.

19. Phypers B, Pierce JT. Lactate physiology in health and disease. Contin Educ Anaesth Crit Care Pain. 2006;6(3):128-132. doi:10.1093/ bjaceaccp/mkl018.

20. Rastegar A. Use of the AG/ $\mathrm{HCO} 3$ Ratio in the Diagnosis of Mixed Acid-Base Disorders. J Am Soc Nephrol JASN. 2007; 18: 2429-2431. doi: 10.1681/ASN.2006121408.

21. Edelmann $C M$, Soriano JR, Boichis $H$, Gruskin AB, Acosta MI. Renal bicarbonate reabsorption and hydrogen ion excretion in normal infants. J Clin Invest. 1967;46(8):13091317. doi:10.1172/JCI105623.
22. Hoffman RS, Smilkstein MJ, Howland MA, Goldfrank LR. Osmol gaps revisited: normal values and limitations. J Toxicol Clin Toxicol. 1993; 31(1): 81-93. doi: 10.3109/15563659309000375.

23. Kraut JA, Madias NE. Consequences and therapy of the metabolic acidosis of chronic kidney disease. Pediatr Nephrol Berl Ger. 2011; 26(1):19-28. doi:10.1007/s00467-010-1564-4.

24. Parker MJ, Parshuram CS. Sodium bicarbonate use in shock and cardiac arrest: attitudes of pediatric acute care physicians. Crit Care Med. 2013;41(9): 2188-2195. doi: 10.1097/ CCM.0b013e31828a6669.

25. Sabatini S, Kurtzman NA. Bicarbonate Therapy in Severe Metabolic Acidosis.J Am Soc Nephrol. 2009; 20(4): 692-695. doi: 10.1681/ ASN.2007121329.

26. Burger $M$, Schaller DJ. Metabolic Acidosis. In: StatPearls. StatPearls Publishing; 2020.Accessed October 27, 2020. http://www. ncbi.nlm.nih.gov/books/NBK482146/.

\section{Kiran HS, Anil GD, Murthy KAS, Gowdappa} HB. Severe Metabolic Acidosis in Critically III Patients and Its Impact on the Outcome; A Prospective Observational Study. 2015; 3(8):4.

28. Nguyen Tien Manh (2020). Giá trị tiên lượng của khoảng trống anion ở bệnh nhân nhiễm toan chuyển hóa tại khoa Điều trị tích cực Bệnh viện Nhi Trung ương, Luận văn Thạc sĩY học, ĐHY Hà Nội. 
PHẦN TỔNG QUAN 
TẠP CHÍ NHI KHOA 2021, 14, 2 
PHẦN TỔNG QUAN 
TẠP CHÍ NHI KHOA 2021, 14, 2 
PHẦN TỔNG QUAN 
TẠP CHÍ NHI KHOA 2021, 14, 2 
PHẦN TỔNG QUAN 
TẠP CHÍ NHI KHOA 2021, 14, 2 
PHẦN TỔNG QUAN 
TẠP CHÍ NHI KHOA 2021, 14, 2 
PHẦN TỔNG QUAN 
TẠP CHÍ NHI KHOA 2021, 14, 2 
PHẦN TỔNG QUAN 
TẠP CHÍ NHI KHOA 2021, 14, 2 
PHẦN TỔNG QUAN 
TẠP CHÍ NHI KHOA 2021, 14, 2 
PHẦN TỔNG QUAN 
TẠP CHÍ NHI KHOA 2021, 14, 2 
PHẦN TỔNG QUAN 
TẠP CHÍ NHI KHOA 2021, 14, 2 
PHẦN TỔNG QUAN 
TẠP CHÍ NHI KHOA 2021, 14, 2 
PHẦN TỔNG QUAN 
TẠP CHÍ NHI KHOA 2021, 14, 2 
PHẦN TỔNG QUAN 
TẠP CHÍ NHI KHOA 2021, 14, 2 
PHẦN TỔNG QUAN 
TẠP CHÍ NHI KHOA 2021, 14, 2 
PHẦN TỔNG QUAN 
TẠP CHÍ NHI KHOA 2021, 14, 2 
PHẦN TỔNG QUAN 
TẠP CHÍ NHI KHOA 2021, 14, 2 
PHẦN TỔNG QUAN 
TẠP CHÍ NHI KHOA 2021, 14, 2 
PHẦN TỔNG QUAN 
TẠP CHÍ NHI KHOA 2021, 14, 2 
PHẦN TỔNG QUAN 
TẠP CHÍ NHI KHOA 2021, 14, 2 
PHẦN TỔNG QUAN 
TẠP CHÍ NHI KHOA 2021, 14, 2 
PHẦN TỔNG QUAN 